\title{
Antibody blockade of the Cripto CFC domain suppresses tumor cell growth in vivo
}

\author{
Heather B. Adkins, ${ }^{1}$ Caterina Bianco, ${ }^{2}$ Susan G. Schiffer, ${ }^{1}$ Paul Rayhorn, ${ }^{1}$ \\ Mohammad Zafari, ${ }^{1}$ Anne E. Cheung, ${ }^{1}$ Olivia Orozco, ${ }^{1}$ Dian Olson, ${ }^{1}$ \\ Antonella De Luca, ${ }^{3}$ Ling Ling Chen, ${ }^{1}$ Konrad Miatkowski ${ }^{1}$ Chris Benjamin, ${ }^{1}$ \\ Nicola Normanno, ${ }^{3}$ Kevin P. Williams, ${ }^{1}$ Matthew Jarpe,${ }^{1}$ Doreen LePage, ${ }^{1}$ \\ David Salomon, ${ }^{2}$ and Michele Sanicola ${ }^{1}$ \\ ${ }^{1}$ Biogen Inc., Cambridge, Massachusetts, USA \\ ${ }^{2}$ National Cancer Institute, Bethesda, Maryland, USA \\ ${ }^{3}$ Oncologia Sperimentale D, Istituto Nazionale per lo Studio e la Cura dei Tumori-Fondazione Pascale, Naples, Italy
}

\begin{abstract}
Cripto, a cell surface-associated protein belonging to the EGF-CFC family of growth factor-like molecules, is overexpressed in many human solid tumors, including $70-80 \%$ of breast and colon tumors, yet how it promotes cell transformation is unclear. During embryogenesis, Cripto complexes with Alk 4 via its unique cysteine-rich CFC domain to facilitate signaling by the TGF- $\beta$ ligand Nodal. We report, for the first time to our knowledge, that Cripto can directly bind to another TGF- $\beta$ ligand, Activin B, and that Cripto overexpression blocks Activin B growth inhibition of breast cancer cells. This result suggests a novel mechanism for antagonizing Activin signaling that could promote tumorigenesis by deregulating growth homeostasis. We show that an anti-CFC domain antibody, A8.G3.5, both disrupts Cripto-Nodal signaling and reverses Cripto blockade of Activin Binduced growth suppression by blocking Cripto's association with either Alk4 or Activin B. In two xenograft models, testicular and colon cancer, A8.G3.5 inhibited tumor cell growth by up to $70 \%$. Both Nodal and Activin B expression was found in the xenograft tumor, suggesting that either ligand could be promoting tumorigenesis. These data validate that functional blockade of Cripto inhibits tumor growth and highlight antibodies that block Cripto signaling mediated through its CFC domain as an important class of antibodies for further therapeutic development.
\end{abstract}

J. Clin. Invest. 112:575-587 (2003). doi:10.1172/JCI200317788.

\section{Introduction}

Perturbations of signaling pathways controlling cell proliferation, such as pathways regulated by the EGF and TGF- $\beta$ ligand superfamilies, are often associated with cell transformation and malignant tumors. Many components of these two pathways, which include src, ras, EGFR, HER-2, Smad2, Alk4, TGF-ßRII, and PDGFR, have been identified as oncogenes and/or

Received for publication January 7, 2003, and accepted in revised form May 20, 2003.

Address correspondence to: Michele Sanicola, Biogen Inc. 14 Cambridge Center, Cambridge, Massachusetts 02142, USA. Phone: (617) 679-3307; Fax: (617) 914-7140;

E-mail: michele_sanicola@biogen.com.

Kevin P. Williams' present address is: Amphora Discovery Corp., Research Triangle Park, North Carolina, USA.

Conflict of interest: H.B. Adkins, S.G. Schiffer, P. Rayhorn, M. Zafari, A.E. Cheung, O. Orozco, D. Olson, L.L. Chen, K. Miatkowski, C. Benjamin, K.P. Williams, M. Jarpe, and D. LePage are employees of Biogen Inc. D. Salomon is a collaborator with Biogen Inc.

Nonstandard abbreviations used: Activin (Act); Act type II receptor (ActRII); Cripto, FRL-1, and Cryptic domain (CFC domain); recombinant human Cripto (hCr); hCr expressed as a human $\mathrm{IgG}_{1} \mathrm{Fc}$ fusion protein $(\mathrm{Cr}-\mathrm{hFc}) ; \mathrm{HA}$, hemagglutinin; forkhead activin signal transducer (FAST). tumor suppressors and have been actively pursued as drug targets (1). Success in the clinic with therapeutics that modulate cell signaling pathways has been documented with mAb's against HER-2 (trastuzumab, Herceptin; Genentech Inc., South San Francsico, California, USA) and EGFR (IMC-C225) (for review see ref. 2), as well as with small-molecule inhibitors of PDGFR tyrosine kinase activity (3). These successes highlight the importance of studying signaling molecules known to be perturbed in cancer and evaluating them as therapeutic intervention points.

Cripto, a glycosylphosphatidylinositol-linked (GPIlinked) membrane protein, is overexpressed in $75-80 \%$ of human breast, colon, and lung cancers, as well as $50-60 \%$ of testicular, stomach, pancreatic, and ovarian cancers (4). In addition, the level of Cripto expression increases with the degree of dysplasia in several of these cancers. In vitro, Cripto exhibits many properties of an oncogene, including transformation of immortalized cells, induction of cell migration, and stimulation of branching morphogenesis (4). Furthermore, antisense inhibition of Cripto expression in colon cancer cells inhibits their growth in soft agar and their tumor-forming potential (5). Evidence in vivo that 
Cripto overexpression induces tumor formation comes from studies of MMTV-Cripto transgenic mice that overexpress Cripto in the mammary gland. Hyperplasias are seen in these mice, and papillary carcinomas develop in aged, multiparous animals (C. Wechselberger and D. Salomon, unpublished observations).

Genetic experiments in mice and zebrafish defined Cripto as a coreceptor for Nodal, a TGF- $\beta$ family ligand (6-10). Cripto-dependent Nodal signaling is required for early embryogenesis, and signaling depends on the Activin type II serine/threonine kinase receptor (ActRII) and the Activin type I serine/threonine kinase receptor (Alk4), which, once activated, phosphorylate the downstream transcriptional coactivator Smad2 (11-13). Human Cripto is the original member of the EGF-CFC family of proteins defined by two conserved adjacent functional motifs: a variant EGF ("EGF-like") domain and a unique cysteine-rich domain, the CFC domain (named for Cripto, FRL-1, and Cryptic). Site-directed mutagenesis experiments demonstrated that Cripto binds to Alk4 through its CFC domain to facilitate signaling through the Smad pathway $(12,14)$. Our group has previously shown that fucosylation of Cripto at a unique glycosylation site within the EGF-like domain is essential for Nodal signaling (15), and mutations in the EGF-like domain have been shown to disrupt Cripto-Nodal interactions (12). Although these experiments have characterized Cripto-Nodal signaling in the embryo, they do not necessarily predict Cripto's function in cancer. Nodal expression is predominantly embryonically restricted, raising the question of whether Cripto could be modulating other TGF- $\beta$ family members in adult tissues.

The role of TGF- $\beta$ family members as tumor suppressors and promoters in cancer is well documented (16-19). In normal tissue, TGF- $\beta$ plays a tumor-suppressive role, but during tumorigenesis, TGF- $\beta$ promotes tumor progression as changes in its expression and decreased cellular response to TGF- $\beta$ favor its oncogenic properties (19). Furthermore, recent reports have shown positive effects of blocking the TGF- $\beta$ pathway as a potential therapeutic approach for the treatment of breast cancer $(20,21)$. Like TGF- $\beta$, Activins, which consist of dimers of $\beta$ subunits ( $\beta$ A or $\beta B)$, are reported to be tumor suppressive for breast, liver, and kidney cells (18). In prostate cancer, reduced ActRII expression is correlated with malignant progression (22), and in pancreatic cancer, mutations in Alk4 have been reported (23). Resistance to Activininduced growth suppression in some breast epithelial cell lines has been attributed to downregulation of either ActRII or Alk4, or loss of Smad4 expression (24). Thus, alterations in Activin receptor function that result in loss of response to Activin may be an important early step in tumorigenesis.

In the present study, we investigated Cripto's role in modulating signaling by TGF- $\beta$ family ligands in cancer cells using mAb's specific to different domains of Cripto, and we investigated whether functional blockade of
Cripto could inhibit tumor cell growth in vivo. Because Activin, like Nodal, utilizes ActRII and Alk4 to signal through the Smad pathway, we examined whether Cripto could modulate Activin signaling via its interaction with Alk4. We present evidence that Cripto can antagonize Activin B-induced growth suppression, but not Activin A-induced growth suppression, in breast cancer cells by directly interacting with Activin B. Furthermore, Cripto's antagonism of Activin B (Act B) can be reversed by an anti-CFC domain Cripto antibody that blocks Cripto-Alk4 binding. These data suggest a novel Criptodependent mechanism for deregulating cell growth homeostasis that could promote tumorigenesis. Moreover, we present evidence for Nodal expression in fully transformed testicular and colon cancer cell lines, and evidence that antibodies to both Cripto EGF and CFC domains will block Nodal signaling in these cells. Finally, we demonstrate that a Cripto anti-CFC domain antibody, which can disrupt both Cripto-Nodal signaling and Cripto-Act B interactions, inhibits the growth of testicular and colon cancer xenograft models in vivo, and we highlight blockade of Cripto function through its CFC domain as a therapeutic intervention point.

\section{Methods}

Production and screening of anti-buman Cripto $m A b$ 's. Experimental procedures involving the use of animals were approved by the Biogen Institutional Animal Care and Use Committee. Mice were immunized intraperitoneally with $25 \mu \mathrm{g}$ of recombinant human Cripto $(\mathrm{hCr})$ expressed as a human $\operatorname{IgG}_{1} \mathrm{Fc}$ fusion protein $(\mathrm{Cr}-\mathrm{hFc})$ with incomplete Freund's adjuvant (Invitrogen Life Technologies, Carlsbad, California, USA) administered intraperitoneally at a different site and boosted three times. Mice were boosted intraperitoneally with $100 \mu \mathrm{g}$ Cr-hFc 3 days before fusion and boosted intravenously with $100 \mu \mathrm{g}$ Cr-hFc 1 day before fusion. Mouse spleen cells were fused with FL653 myeloma cells at a ratio of one spleen cell to six myeloma cells and plated into 96well plates in selection media. Hybridoma supernatants were initially screened by flow cytometry for binding to cell surface-expressed Cripto on human tumor cell lines, including NTERA (embryonic carcinoma), NCCIT (testicular), and SiHa (cervical). Classification of mAb's into distinct groups was based on their reactivity in an ELISA assay to different domains of $\mathrm{hCr}$ expressed as hFc fusion proteins: $\mathrm{Cr}-\mathrm{hFc}$ (amino acids 1-169), CrEGF-hFc (amino acids 75-112), and CrCFChFc (amino acids 112-169). Cripto proteins were coated on 96-well plates for 1 hour at $37^{\circ} \mathrm{C}$ in $0.1 \mathrm{M}$ $\mathrm{NaHPO}_{4}(\mathrm{pH} 9.0)$ at $0.5 \mu \mathrm{g} / \mathrm{ml}, 100 \mu \mathrm{l} /$ well, and blocked with $\mathrm{PBS} / 10 \%$ donor calf serum. Antibodies diluted in PBS/0.05\% Tween-20 were incubated for 1 hour at $37^{\circ} \mathrm{C}$, washed with PBS/0.05\% Tween-20, and probed with anti-mouse HRP-conjugated antibody (Pierce Chemical Co., Rockford, Illinois, USA). Bound antibodies were detected by 3,3'-5,5'-tetramethylbenzidine, stopped with $1 \mathrm{~N} \mathrm{H}_{2} \mathrm{SO}_{4}$, and read at $450 \mathrm{~nm}$. None of these mAb's bound LT $\beta$ R-hFc, which was used as a 
negative control protein. The $\mathrm{mAb}$ 's were further characterized for competition for binding $\mathrm{Cr}-\mathrm{hFc}$ using Biacore technology (Biacore Inc., Piscataway, New Jersey, USA), and binding to Cripto-specific peptides by ELISA. Immunohistochemistry. Immunohistochemical localization was performed with anti-Cripto mAb's A10.B2.18 (breast and NCCIT) or B3.F6.17 (colon and GEO) using a VECTASTAIN Elite peroxidase kit (Vector Laboratories Inc., Burlingame, California, USA). Mouse IgG was used as a negative control for all samples. Paraffin sections of colon tumor tissue (Imgenex, San Diego, California, USA), breast tumor tissue (Novagen, Madison, Wisconsin, USA), and NCCIT and GEO tumor cells, passaged once in an athymic nude mouse, were deparaffinized and rehydrated before incubation in $1 \% \mathrm{H}_{2} \mathrm{O}_{2} /$ methanol to block endogenous peroxidase. After blocking in $2 \%$ goat serum in PBS, sections were incubated with $2 \mu \mathrm{g} / \mathrm{ml}$ primary antibody in blocking solution overnight at $4^{\circ} \mathrm{C}$. Sections were treated with biotinylated anti-mouse IgG then avidin-biotinylated HRP complex. Color was developed using Vector NovaRED or DAB substrate kits (Vector Laboratories Inc.). Sections were counterstained with hematoxylin. Immunofluorescence was performed essentially the same way, but using $1 \%$ BSA in PBS as blocking reagent, $2 \mu \mathrm{g} / \mathrm{ml} \mathrm{A10.B2} .18$ or 1E6, and $\mathrm{Cy} 3$-conjugated anti-mouse secondary antibody at 1:300 (Jackson ImmunoResearch Laboratories Inc., West Grove, Pennsylvania, USA).

Protein expression and purification, FACS and signaling assays. $\mathrm{Cr}-\mathrm{hFc}$, CrEGF-hFc, and $\mathrm{CFC}-\mathrm{hFc}$ were expressed and purified as described (15). Cripto CFC-hFc (amino acids 112-169) was generated by PCR amplification and subcloned as described before (15). FACS analysis was performed essentially as described before (11). For Alk4 blocking studies, 293 cells were cotransfected with a plasmid expressing Alk4 with a C-terminal hemagglutinin (HA) epitope tag (Alk4-HA) (gift of M. Whitman, Harvard Medical School, Boston, Massachusetts, USA) and a puromycin expression plasmid at a 10:1 ratio to generate a clonal cell line, as previously described (25). For blocking, $10 \mu \mathrm{g} / \mathrm{ml}$ of Cr-hFc was preincubated on ice with $20 \mu \mathrm{g} / \mathrm{ml}$ of $\mathrm{mAb}$ before addition to cells. Signaling assays were performed essentially as described previously (15). Briefly, NCCIT or T47D cells were transfected with $15 \mathrm{ng} /$ well (n2) 7 -luciferase, $100 \mathrm{ng} /$ well forkhead activin signal transducer (FAST) transcription factor, and/or $100 \mathrm{ng} /$ well Nodal expression plasmid (gift of E. Robertson, Harvard University, Cambridge, Massachusetts, USA) on a 24-well plate. Alternatively, cells were treated with $25 \mathrm{ng} / \mathrm{ml}$ Act B. Antibodies were added on the first day of transfection and again 24 hours before luciferase reading.

Growth inhibition assays. T47D cells (American Type Culture Collection, Manassas, Virginia, USA) were transfected with an ecotropic receptor expression plasmid (EcoR; gift of B. Elenbaas, Biogen Inc., Cambridge, Massachusetts, USA) and selected in RPMI/10\% FCS/10 $\mu \mathrm{g} / \mathrm{ml}$ insulin containing $100 \mu \mathrm{g} / \mathrm{ml}$ hygromycin. A polyclonal line of T47D-EcoR that permitted infection of pBABE-GFP murine leukemia virus (MLV) was grown out, infected with $\mathrm{pBABE}-\mathrm{hCr}$-PURO MLV, and selected in puromycin media. This oligoclonal line (T47D-hCr) was analyzed by FACS for hCr expression with specific anti-Cripto antibodies. Approximately 4,000 cells per well of T47D-EcoR or T47D-hCr were plated in a 96-well plate in media containing $2 \%$ serum with or without $10 \mathrm{ng} / \mathrm{ml}$ Activin A (Act A) or Act B (R\&D Systems Inc., Minneapolis, Minnesota, USA) or $10 \mu \mathrm{g} / \mathrm{ml}$ A8.G3.5. Medium with factors was replaced daily for 7-8 days. The plate was harvested by addition of $20 \mu \mathrm{l} /$ well CellTiter AQueous One solution (Promega Corp., Madison, Wisconsin, USA), incubation for 2 hours at $37^{\circ} \mathrm{C}$, and reading at $490 \mathrm{~nm}$.

Immunoprecipitations and immunoblots. Cr-hFc $(1 \mu \mathrm{g})$ was prebound to protein A-Sepharose in NP40 buffer and then incubated with $1 \mu \mathrm{g}$ of Act A or Act B (R\&D Systems Inc.) at $4^{\circ} \mathrm{C}$ overnight. Immunoprecipitated protein was washed three times in ice-cold NP40 buffer, and a portion of the sample was run on a polyacrylamide gel and then blotted with either anti-Act A or anti-Act B mAb's (R\&D Systems Inc.). For antibody blocking, $1 \mu \mathrm{g}$ of $\mathrm{Cr}-\mathrm{hFc}$ was incubated with the indicated amount of antibody prior to binding to protein ASepharose. For the CrEGFmt-hFc experiment, $100 \mu$ l of unpurified cell supernatant from 293 cells expressing the $\mathrm{hFc}$ proteins was prebound to protein A-Sepharose for 1 hour at $4^{\circ} \mathrm{C}$. Then $1 \mu \mathrm{g}$ of Act B or $1.5 \mathrm{ml}$ of 293 cell supernatant expressing Nodal was added and incubated at $4^{\circ} \mathrm{C}$ overnight. Nodal was detected using a rabbit polyclonal antibody against a Nodal-specific peptide.

For phospho-Smad and MAPK analysis, T47D or T47D-hCr cells were plated at $4 \times 10^{6}$ cells $/ \mathrm{ml}$ in $100-$ $\mathrm{mm}$ dishes. Cells were serum-starved overnight and incubated with indicated amounts of Act A, Act B, or EGF for the indicated time. Cells were lysed in NP40 buffer containing protease inhibitors, $1 \mathrm{mM}$ sodium orthovanadate, and $20 \mathrm{mM}$ sodium fluoride, separated on a polyacrylamide gel, and blotted onto nitrocellulose. The membrane was immunoblotted with phosphoSmad2 antibody or p44/42 MAPK antibody (Cell Signaling Inc., Beverly, Massachusetts, USA) and bound antibody was probed with peroxidase-conjugated donkey anti-rabbit IgG antibody (Jackson ImmunoResearch Laboratories Inc., West Grove, Pennsylvania, USA). For Cripto analysis in tumor lines, cells were lysed in RIPA buffer plus protease inhibitors, and 6,15 , and $30 \mu \mathrm{g}$ of total protein lysate (CHO, NCCIT, and GEO, respectively) was separated on a $10-20 \%$ SDS polyacrylamide gel and transferred to nitrocellulose. The blot was probed with $0.1 \mu \mathrm{g} / \mathrm{ml}$ A10.B2.18 and detected with anti-mouse-HRP. Immunoreactivity was revealed using SuperSignal West Dura Substrate (Pierce Chemical Co.). Biacore studies. Cr-hFc and $\mathrm{LT} \beta \mathrm{R}-\mathrm{hFc}$ were immobilized by standard amine coupling to CM5 sensor chips (Pharmacia Biosensor AB) (26), and Act A or $B$ at $5 \mu \mathrm{g} / \mathrm{ml}$ was then captured in HBS buffer $(10$ mM HEPES, $150 \mathrm{mM} \mathrm{NaCl}, 3.4 \mathrm{mM}$ EDTA, 0.005\% 
Biacore surfactant P20, pH 7.4; Biacore Inc.). Experiments were performed at $25^{\circ} \mathrm{C}$ with a $10-\mu \mathrm{l} / \mathrm{min}$ flow rate. For data analysis, nonspecific binding to the blank-flow cell was subtracted from each sensorgram to obtain specific-binding responses using BIAevaluation 3.0 software (Biacore Inc.).

Human xenograft tumor models. NCCIT, a mediastinal mixed germ cell human testicular carcinoma cell line (American Type Culture Collection), was maintained in RPMI 1640/10\% FBS without antibiotics. GEO, a carcinoma cell line (American Type Culture Collection), was maintained in DMEM/10\% FBS without antibiotics. Male athymic nude mice, 6-8 weeks old (Harlan Sprague Dawley Inc., Indianapolis, Indiana, USA), were acclimated for 1 week before the study. The day before tumor implantation, mice were numbered and randomized into treatment $(n=10)$ and vehicle control $(n=30)$ groups, initial body weights were recorded, and the first treatments were administered. Studies were run as randomized, double-blinded trials. Antibodies were administered intraperitoneally on a q14d treatment schedule (dosing every 14 days). Clinical-grade Platinol-AQ, cisplatin injection (Bristol-Myers Squibb Co., Seattle, Washington, USA), was the positive chemotherapeutic control agent, administered subcutaneously on a q2dx6 schedule (i.e., dosing every other day for a total of 6 treatments). Animals were implanted (day 0) subcutaneously with $5 \times 10^{6}$ cells (with $0.2 \mathrm{ml}$ matrigel for NCCIT cells). Tumors were measured every 3 or 4 days. Tumor size ( $\mathrm{mm}$ ) was converted to volume ( $\mathrm{mg}$ ) using the formula $\left(\right.$ length $\times$ width $\left.{ }^{2}\right) / 2$. Data are reported as change in tumor weight with tumors normalized to each animal's first tumor measurement.

RT-PCR. Methods and primers for RT-PCR analysis of hCripto and Alk4 were previously described (27, 28). Because the human homolog of murine Nodal has not been confirmed, we used primers based on a human Nodal-like cDNA sequence in the GenBank database (accession no. AI050866): 5'-CATGAAAGCTATAGGTGACTTCATCC-3' (Nodal-like foreword), 5' TGTAAATGAAGGGCTCAGTGGA-3' (Nodal-like reverse) (29) Human Act B primers are 5'-TGAAGCGGCACATCTTGAGC-3' (hAct B forward) and 5'-ACACTTTGACCCGCACCTTC-3' (hAct B reverse). Murine Act $B$ primers were previously published (30). RT-PCR from NCCIT and GEO cell lines was performed essentially as described previously $(28,29)$. RNA and subsequent cDNA were prepared from NCCIT xenograft tumor using RNeasy Protect Kit (QIAGEN Inc., Valencia, California, USA) and SuperScript First-Strand Synthesis System (Invitrogen Corp., San Diego, California, USA) with random-hexamer priming. PCR reactions were then performed with Advantage $2 \mathrm{PCR}$ kit (CLONTECH Laboratories Inc., Palo Alto, California, USA) for 30 cycles at an annealing temperature of $62^{\circ} \mathrm{C}$ using the Nodal or murine Act B primer sets. Resulting PCR products were subcloned into pCRII-TOPO vector (Invitrogen Corp.), and the sequences were confirmed.

\section{Results}

Generation of Cripto $m A b$ 's that recognize functionally important epitopes. A panel of murine $\mathrm{mAb}$ 's against recombinant human Cripto ( $\mathrm{hCr}$ ) expressed as human $\mathrm{IgG}_{1} \mathrm{Fc}$ fusion protein $(\mathrm{Cr}-\mathrm{hFc})$ was generated (Table 1$)$. AntiCripto mAb's were identified by their ability to bind to human tumor cell lines known to express Cripto and by their ability to bind to Cripto EGF and CFC domains by ELISA (see Methods). Based on this analysis, four classes of mAb's were found: N-terminal "tip," $\mathrm{N}$-terminal, EGF domain, and CFC domain (Table 1 and Figure 1a). These antibodies were tested for crossreactivity to human Cryptic, a closely related family member, by binding in a flow cytometry assay to 293 cells expressing an HA-tagged human Cryptic expression plasmid. Although Cryptic expression was confirmed by Western blotting with an anti-HA polyclonal antibody, no cross-reactivity of these Cripto antibodies to Cryptic was observed (see Supplemental Figure 2; www.jci.org/cgi/content/full/112/4/575/ DC1). The ability of these mAb's to recognize key signaling domains of Cripto was examined by analysis of binding to Cripto mutants. Mutations in the EGF domain (N85G/T88A) prevent fucosylation of Cripto, disrupting its ability to bind Nodal and signal through Smad2 $(12,15,31)$. Cripto mAb's were tested for binding to hCr(N85G/T88A) expressed on human 293 cells by flow cytometry, and no difference was observed in binding to the fucosylation mutant compared with wild-type hCr, with the exception of the anti-EGF $\mathrm{mAb}$ 's (Table 1). Cripto mAb's were also tested for binding to a Cripto CFC domain mutant, hCr(H120G/ W123G), which abrogates Cripto binding to Alk4 (12). Only the anti-CFC mAb's, A8.G3.5, A10.A10.30, and A6.C12.11, failed to bind to this mutant (Table 1). Thus, we have identified anti-EGF domain and anti-CFC domain Cripto mAb's that specifically recognize the epitopes defined by mutational analysis to be necessary for Cripto-Nodal signaling.

Cripto mAb's were further characterized by immunohistochemical and immunofluorescent staining of Cripto expression on various tumor samples and tumor cell lines with N-terminal mAb's A10.B2.18 and B3.F6.17. These two antibodies recognize the same $\mathrm{N}$-terminal Cripto peptide sequence and cross-block each other for binding to Cripto by Biacore analysis (data not shown). Thus, A10.B2.18 and B3.F6.17 recognize indistinguishable epitopes. By Western blot, A10.B2.18 recognizes two Cripto protein bands between 15 and $18 \mathrm{kDa}$ in both $\mathrm{CHO}$ cells expressing recombinant Cripto protein and NCCIT and GEO tumor cell lines expressing tumor-derived Cripto (Figure 1b). Similar results were obtained with B3.F6.17 (data not shown). We tested whether these antibodies recognize cell surface-associated Cripto on human breast tumor samples. Indeed, predominant cell surface staining was observed with A10.B2.18 (Figure 1c) or B3.F6.17 (data not shown), whereas the isotype control antibody, anti-human LFA3 1E6, did not stain the 
Table 1

Anti-Cripto mAb's map to different functional domains

\begin{tabular}{lccccc}
\hline & \multicolumn{3}{c}{ ELISA $^{\mathrm{A}}$} & \multicolumn{3}{c}{ FACS (\%) } \\
Antibody & Cr & CrEGF & CrCFC & N85G/T88A & H120G/W123G \\
A8.H3.2 & + & + & - & 100 & 118 \\
A19.E2.7 & + & + & - & ND & ND \\
B3.F6.17 & + & - & - & 111 & 142 \\
A10.B2.18 & + & - & - & 90 & ND \\
A27.F6.1 & + & + & - & 15 & 121 \\
A8.H3.1 & + & + & - & 3 & 149 \\
A40.G12.8 & + & + & - & 16 & 176 \\
B6.G7.10 & + & + & - & 41 & 166 \\
A10.A10.30 & + & - & + & 83 & 29 \\
A8.G3.5 & + & - & + & 45 & 1 \\
A6.F8.6 & + & - & + & 109 & 87 \\
A6.C12.11 & + & - & + & 84 & 21
\end{tabular}

${ }^{\mathrm{A}} \mathrm{Cr}$, $\mathrm{CrEGF}$, and $\mathrm{CrCFC}$ correspond to the hFc fusion proteins coating the ELISA plate, and plus symbols represent positive binding of the mAb's to these proteins. BFACS binding is represented as the mean fluorescence intensity of the mAb binding to the $\mathrm{hCr}$ mutant expressed on 293 cells as a percentage of the $\mathrm{mAb}$ binding to wild-type $\mathrm{hCr}$ in the same experiment. Color code of antibodies corresponds to binding regions shown in Figure 1a. ND, not done.

tumor tissue. In agreement with previously published data using a Cripto polyclonal antibody (32), some Cripto expression is also seen in the cytoplasm. An example of immunohistochemical staining of Cripto overexpression in human breast and colon tumor tissue and human NCCIT testicular cell and GEO colon cell xenograft tumor samples is shown in Figure 1d. Our results with these mAb's in human breast and colon tumor samples $(n>50)$ are in agreement with published Cripto polyclonal antibody staining data in which Cripto overexpression was detected in approximately $80 \%$ of breast and colon cancers $(28,32,33)$.

Cripto antibodies inhibit Cripto-Nodal signaling in transformed cells. Anti-Cripto mAb's were analyzed for blocking known signaling functions of human Cripto. Cripto binds Nodal via its EGF-like domain (12), and we previously showed that the EGF domain fucosylation mutant (N85G/T88A) disrupts Cripto-Nodal signaling in a FAST transcription factor-dependent $(\mathrm{n} 2)_{7}{ }^{-}$ luciferase reporter assay (15). Therefore, we tested whether anti-EGF domain mAb's could inhibit Cripto-dependent Nodal signaling in this assay. Anti-EGF domain $\mathrm{mAb}$ A27.F6.1, which does not recognize the Cripto fucosylation mutant (Table 1), was tested for inhibition of Cripto-dependent Nodal activation of FAST/(n2) 7 -luciferase in NCCIT cells. At concentrations of $1-30 \mu \mathrm{g} / \mathrm{ml}$, A27.F6.1 decreased the luciferase activity by $48-66 \%$ in the presence of Nodal (Figure 2a), indicating that anti-EGF domain mAb A27.F6.1 could inhibit Cripto-dependent Nodal signaling through the Smad2/3 pathway in this transformed human cell line.

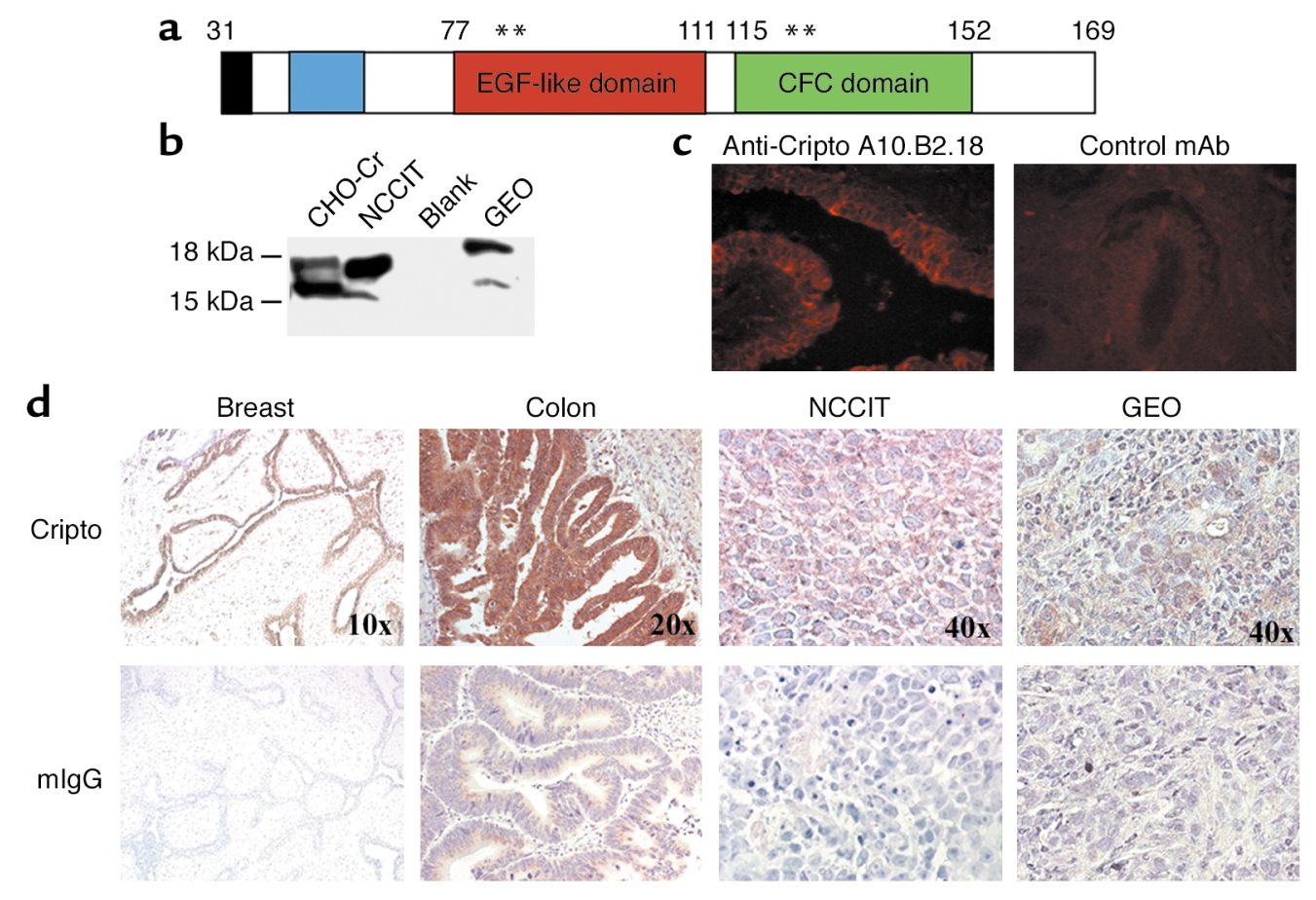

\section{Figure 1}

(a) Diagram of mature hCr protein: N-terminal tip (black), N-terminal region (blue), EGF-like domain (red), and CFC domain (green). Amino acid 169 is $\mathrm{N}$-terminal to the GPI-linkage site. Asterisks indicate positions of mutants described in Table 1. (b) Western blot of Cripto expressed in $\mathrm{CHO}$ cells (recombinant) or endogenously expressed in NCCIT and GEO tumor cell lines using A10.B2.18. (c) Immunofluorescent staining of cell surface Cripto on human breast tumor tissue with A10.B2.18 (left) or control antibody $1 \mathrm{E6}$ (right). (d) Immunohistochemical staining of tumor sections with anti-Cripto mAb's A10.B2.18 (breast and NCCIT) and B3.F6.17 (colon and GEO) or mouse IgG as a negative control. Color variations result from the use of different substrates, either Vector NovaRED or DAB substrate kits (Vector Laboratories Inc.). 


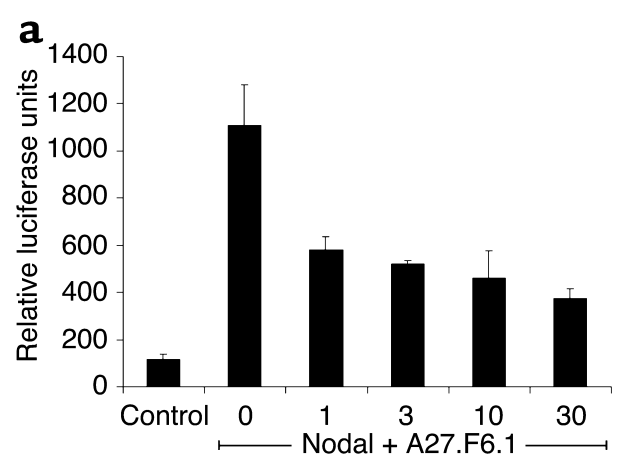

b
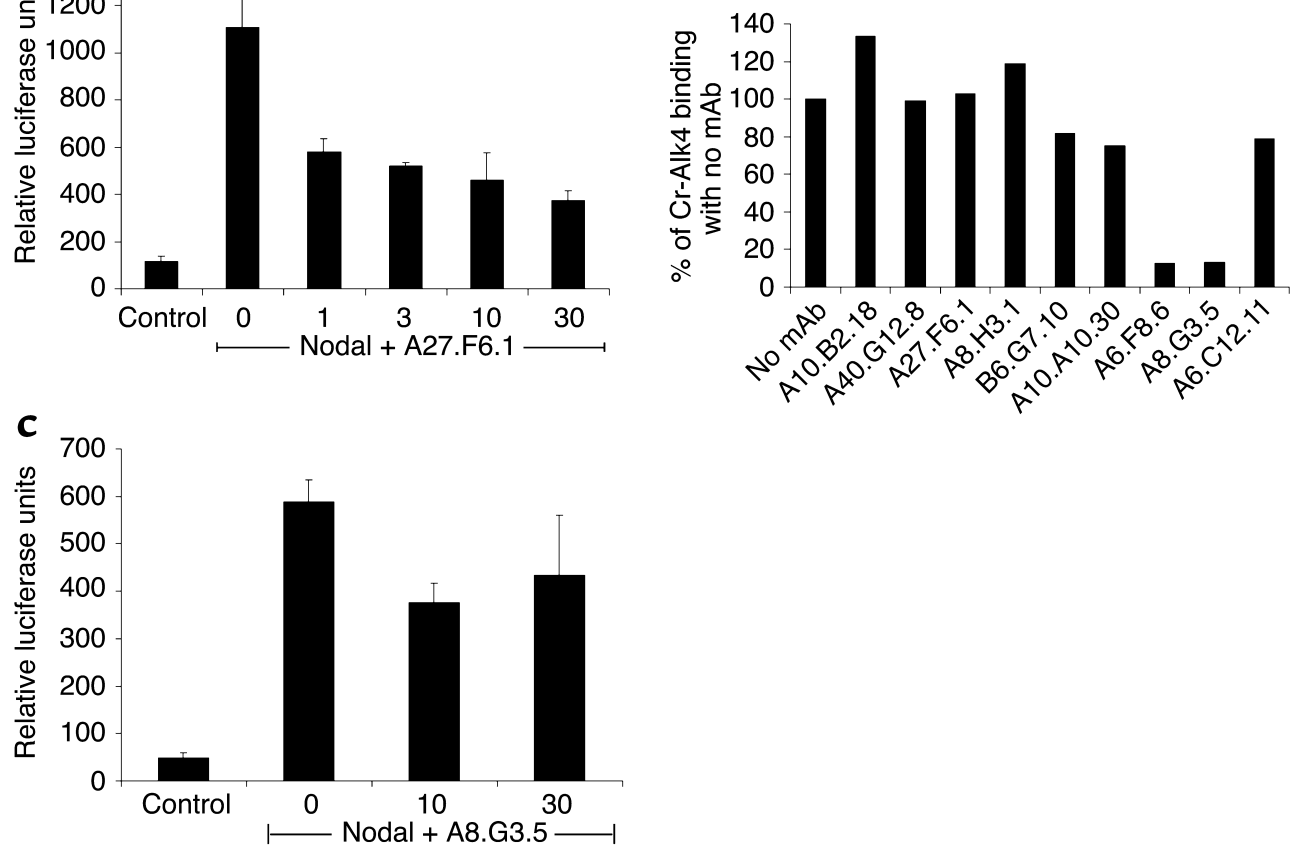

Figure 2

Anti-CFC mAb's block Nodal signaling and Cripto-Alk4 interactions. (a) NCCIT cells were transfected with plasmids expressing ( $\mathrm{n} 2)_{7}-$

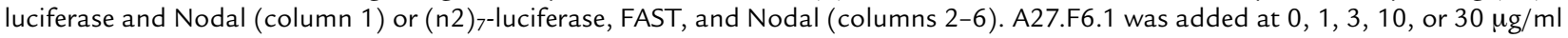
for 16 hours before luciferase reading $(P<0.001$ for each dose). (b) Human 293-Alk4 cells were incubated with $\mathrm{Cr}$-hFc or Cr-hFc prebound with $\mathrm{mAb}$ and assayed for binding by FACS using an anti-hFc PE-conjugated secondary mAb. The mean fluorescence intensity of $\mathrm{Cr}-\mathrm{hFc} / \mathrm{mAb}$ bound to 293-Alk4 cells is represented as a percentage of $\mathrm{Cr}$-hFc binding with no mAb. (c) NCCIT cells were assayed for blocking of Cripto-Nodal signaling by A8.G3.5 at $10 \mu \mathrm{g} / \mathrm{ml}(P=0.002)$ or $30 \mu \mathrm{g} / \mathrm{ml}(P=0.05)$ as described in a.

We obtained similar results with the anti-EGF domain mAb's A8.H3.1 and A40.G12.8 (data not shown).

Cripto-dependent Nodal signaling is also known to be dependent on Cripto's interaction with Alk 4 via the Cripto CFC domain $(11,12)$. Previously, we reported that $\mathrm{Cr}-\mathrm{hFc}$ binds to Alk 4 expressed on 293 cells in a flow cytometry assay (11). This assay was used to test whether any of the Cripto mAb's could block CriptoAlk4 interactions. Cr-hFc $(10 \mu \mathrm{g} / \mathrm{ml})$ preincubated with the mAb's $(20 \mu \mathrm{g} / \mathrm{ml})$ was added to $293-A l k 4$ cells and assayed for binding by flow cytometry. Anti-CFC domain antibodies A8.G3.5 and A6.F8.6 blocked this interaction by over $90 \%$ (Figure $2 \mathrm{~b}$ ). Other CFC domain $\mathrm{mAb}$ 's, A6.C12.11 and A10.A10.30, were able to block Cripto-Alk 4 interaction by about $30 \%$, while $\mathrm{N}$-terminal mAb's (e.g., A10.B2.18) or EGF domain mAb's (e.g., A27.F6.1) were unable to block Cripto-Alk4 binding. Notably, the mAb's that blocked Cripto-Alk4 binding most effectively are also the mAb's that fail to bind the CFC domain mutant (H120G/W123G) (Table 1).

Anti-CFC mAb's were further tested for their ability to block Cripto-dependent Nodal signaling by presumably blocking Cripto-Alk4 interactions. Anti-CFC mAb A8.G3.5, a potent blocker of Cripto-Alk4 binding, was tested for inhibition of Nodal signaling in NCCIT cells. At 10 and $30 \mu \mathrm{g} / \mathrm{ml}$, A8.G3.5 reproducibly blocked Nodal signaling by about $35 \%$ in this assay (Figure 2c).
No blocking effect was observed at lower concentrations, but similar effects were observed with other anti-CFC domain mAb's (data not shown). These results demonstrate that blocking both the EGF and the CFC domains of Cripto will inhibit Nodal signaling.

Cripto disrupts Act B-induced growth suppression of breast cancer cells. Activin, like Nodal, signals through Alk4, which has been associated with functional alterations and mutations in human cancer $(18,34)$. Therefore, we examined whether Cripto could modulate Activin signaling in cancer cells through its interaction with Alk4. One biological consequence of Activin signaling is inhibition of proliferation of several cell types (18). Although NCCIT cells are responsive to Activin signaling in a FAST/(n2) $)_{7}$-luciferase assay, they are not growth-inhibited by Activin in vitro. Therefore, we chose to use T47D cells, an estrogen receptor-positive human breast cancer cell line that is known to be growth-inhibited by Activin $(35,36)$. Because T47D cells express very low levels of Cripto (data not shown), we generated an oligoclonal T47D line expressing high levels of fulllength Cripto (T47D-hCr) using the pBABE retroviral expression system (37), which contains full-length human Cripto cDNA. Since T47D cells lose responsiveness to Activin through extensive passaging, the nearly $100 \%$ transduction efficiency with this system allowed us to make a cell line with very few passages in culture. 


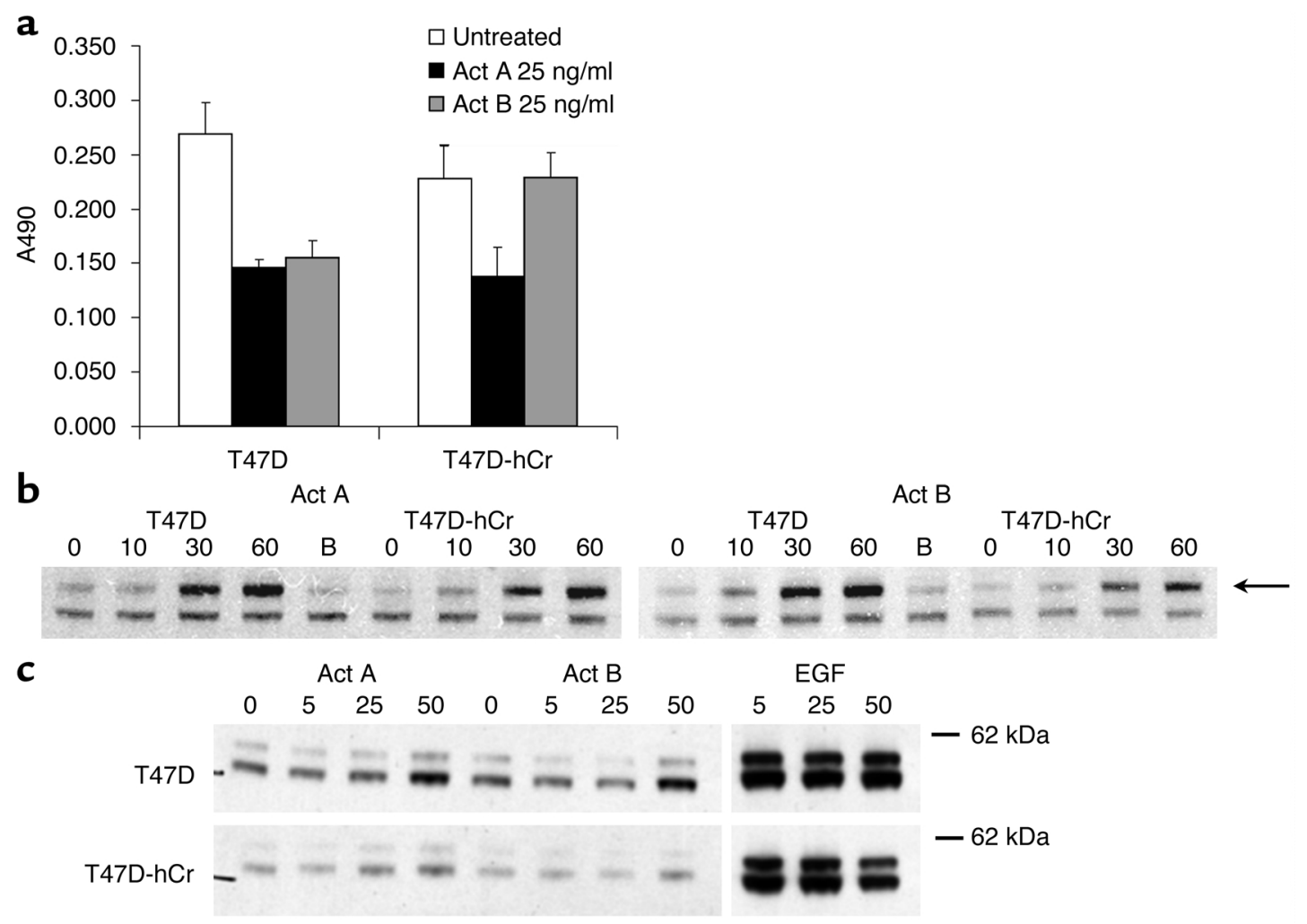

\section{Figure 3}

Overexpression of Cripto blocks Act B growth suppression of breast epithelial cells. (a) T47D or T47D-hCr cells were grown in media alone (white bars) or media plus $25 \mathrm{ng} / \mathrm{ml}$ Act A (black bars) or Act B (gray bars). Proliferation was measured by an MTT assay after 8 days. $n=4$; the experiment was repeated at least twice. (b) Lysates of T47D and T47D-hCr cells stimulated with $25 \mathrm{ng} / \mathrm{ml}$ of Act A (left panel) or Act B (right panel) for 0, 10, 30, and 60 minutes were immunoblotted with anti-phospho-Smad2 polyclonal antibody. B, blank sample of T47D untreated cells. The arrow points to the phospho-Smad2 band. (c) T47D and T47D-hCr cells were stimulated with 0, 5, 25 , or $50 \mathrm{ng} / \mathrm{ml}$ Act A, Act B, or EGF for 1 hour and then lysed and probed for $\mathrm{p} 44 / 42 \mathrm{MAPK}$.

Using flow cytometry and anti-Cripto antibodies, the number of Cripto molecules on T47D-hCr cells was estimated to be 16,000-22,000 per cell, which is comparable to the number on human tumor cell lines that overexpress Cripto, such as NCCIT (10,000 per cell) and GEO (40,000-60,000 per cell; data not shown).

For this study, T47D and T47D-hCr cells were grown in low-serum conditions, with or without $25 \mathrm{ng} / \mathrm{ml} \mathrm{Act}$ $\mathrm{A}$ or Act $\mathrm{B}$, and assayed for proliferating cells using a nonradioactive modified MTT assay. Untreated T47D and T47D-hCr cells did not differ in their proliferation rates either in normal media or in low-serum conditions. However, proliferation of parental T47D cells was inhibited by Act A and Act B by approximately $40 \%$ compared with that of untreated cells (Figure 3a). In contrast, proliferation of T47D-hCr cells was not inhibited by Act B, but, surprisingly, these Cripto-expressing cells were sensitive to growth inhibition by Act A. Therefore, Cripto's inhibitory effect on Activin-induced growth suppression of these cells is specific to Act B.

Next, we examined whether Cripto's effect on Act B signaling inhibits the Smad2 pathway by preventing phosphorylation of the endogenous Smad2 expressed in these cells. T47D and T47D-hCr cells were stimulated with $25 \mathrm{ng} / \mathrm{ml} \mathrm{Act} \mathrm{A} \mathrm{or} \mathrm{Act} \mathrm{B} \mathrm{for} \mathrm{0,} \mathrm{10,} \mathrm{30,} \mathrm{and}$
60 minutes. Lysates were subject to SDS-PAGE and immunoblotted with an anti-phospho-Smad2 polyclonal antibody. Act A stimulated Smad2 phosphorylation in both cell lines in a time-dependent manner, with the highest increase at 60 minutes (Figure 3b). T47D cells treated with Act B showed a similar increase in Smad2 phosphorylation over this time period. However, T47D-hCr cells did not have a significant increase in Smad2 activation until 30 minutes, and the signal was dampened compared with that in parental cells. A smaller, unregulated band was detected by the anti-phospho-Smad2 antibody and serves as a loading control. The decrease and delay in Smad 2 activation by Act B in the T47D-hCr cells indicates that Cripto's antagonism of Act B signaling inhibits the downstream Smad2 pathway.

Cripto has been shown to stimulate p42 MAPK in mammary epithelial cells $(11,38)$, so we examined whether the MAPK pathway could be activated in T47D-hCr cells and whether this pathway is modulated by Activin treatment. We observed no increase in p42 MAPK phosphorylation in T47D-hCr cells compared with the parental cells, and neither Act A nor Act B stimulated p42 MAPK in either cell line (Figure 3c). However, as a control, EGF was able to generate a 
robust p42 MAPK response in both cell lines. The lack of observable MAPK stimulation in T47D-hCr cells could be due to differences in cell lines, or to the use of membrane-bound Cripto in this study versus a soluble Cripto and/or Cripto peptides in previous reports. However, this result supports the conclusion that Cripto antagonizes Act B-induced growth suppression by preventing Act B from signaling through Smad2.

Cripto binds directly to $A c t B$, and binding is blocked by anti$C F C m A b$ A8.G3.5. Because Cripto's effect on the Activin signaling pathway is specific to Act $B$, we examined whether Cripto binds directly to Act B. Act A or Act B was immunoprecipitated with purified $\mathrm{Cr}-\mathrm{hFc}$ prebound to protein A-Sepharose and then immunoblotted with mAb's specific for Act A or B. Indeed, Cr-hFc bound specifically to Act $B$ in this experiment (Figure $4 a)$, indicating that Cripto binds to Act B independently of additional factors. We also analyzed Cripto binding to TGF- $\beta$ family members Act A, Act B, TGF- $\beta 1$, TGF- $\beta 2$, BMP2, BMP7, and GDNF by ELISA and found that Cripto specifically interacted with Act B and not other family members (see Supplemental Figure 1; www.jci.org/cgi/content/full/112/4/575/DC1).

We also analyzed the Cripto-Act B interaction using Biacore technology. Act $\mathrm{B}$ directly bound with high intensity to $\mathrm{Cr}-\mathrm{hFc}$ immobilized on a Biacore chip, but not to a control LT $\beta R$-hFc protein (Figure $4 b$ ). In contrast, the level of Act A binding to $\mathrm{Cr}-\mathrm{hFc}$ was negligible. We estimated that the apparent affinity of $\mathrm{Cr}-\mathrm{hFc}$ binding to Act $\mathrm{B}$ in solution by a competition format assay is about $1 \mathrm{nM}$ (M. Jarpe, unpublished observations). Our results show that Cripto can bind directly to Act $\mathrm{B}$ with a high apparent affinity and fast on and off rates. Future studies will determine whether association with other components, such as Alk4, can stabilize the Cripto-Act B interaction.

Cripto is known to interact with Nodal through its EGF domain, and mutations (N85G/T88A) in the fucosylation site of the EGF domain abrogate Nodal binding $(12,31)$. Therefore, we investigated whether these same residues that are important for Nodal binding would also be critical for Act B binding. A Cr-hFc protein (CrEGFmt-hFc) containing the N85G/T88A double mutations was generated and used to immunoprecipitate Act B. Act B was able to bind equally well to CrEGFmt-hFc as to the wild-type Cr-hFc in this assay (Figure 4c). Due to the present difficulty in purifying active Nodal protein, unpurified Nodal expressed in supernatant of human 293 cells was used in an immunoprecipitation experiment with CrEGFmt-hFc. As expected, Nodal was unable to bind as well to CrEGFmt-hFc protein as it bound to wild-type $\mathrm{Cr}-\mathrm{hFc}$ (Figure 4c). This result indicates that the critical residues of Cripto for Act B binding are different from those that interact with Nodal, and while the fucosylation site of Cripto is necessary for Nodal binding (Figure $4 \mathrm{c}$ and ref. 12), it does not affect Cripto-Act B interactions significantly.

To identify which domain of Cripto is responsible for interaction with Act B, we tested whether anti-N-terminal B3.F6.17, anti-EGF domain A27.F6.1, or anti-CFC domain A8.G3.5 could block Cripto's association with Act $B$ in an immunoprecipitation assay. Purified Cr-hFc was preincubated with different amounts of the $\mathrm{mAb}$ prior to binding to protein A-Sepharose. Act B immunoprecipitation and immunoblotting were then

\section{Figure 4}

Cripto binds directly to $A c t B$, and binding is blocked by anti-CFC mAb A8.G3.5. (a) Act $A$ or Act $B$ was immunoprecipitated with $\mathrm{Cr}$-hFc prebound to protein A-Sepharose. Immunoprecipitated protein was immunoblotted using anti-Act $A$ (left panel) or anti-Act B (right panel) mAb's. Act $A$ and Act $B(10 \mathrm{ng})$ were loaded on each gel for comparison. (b) Act B binds to $\mathrm{Cr}$-hFc in a Biacore assay. Act A (left panels) or B (right panels) was flowed over Biacore chips immobilized with $\mathrm{Cr}$-hFc (top panels) or LT $\beta$ R-hFc (bottom panels) and assayed for binding by surface plasmon resonance using a Biacore 2000 biosensor system (Biacore Inc.). Nonspecific binding to the blankflow cell was subtracted from each sensorgram to obtain the specific-binding responses. RU, resonance units. (c) Purified Act $B$ or cell supernatant containing Nodal was immunoprecipitated with $\mathrm{Cr}$-hFc or CrEGFmt-hFc as described in a. (d) For antibody blocking, Cr-hFc was preincubated with $0.1-3 \mu \mathrm{g}$ of B3.F6.17, A27.F6.1, or A8.G3.5 prior to Act $B$ binding.IP, intraperitoneal. WB, Western blot. a
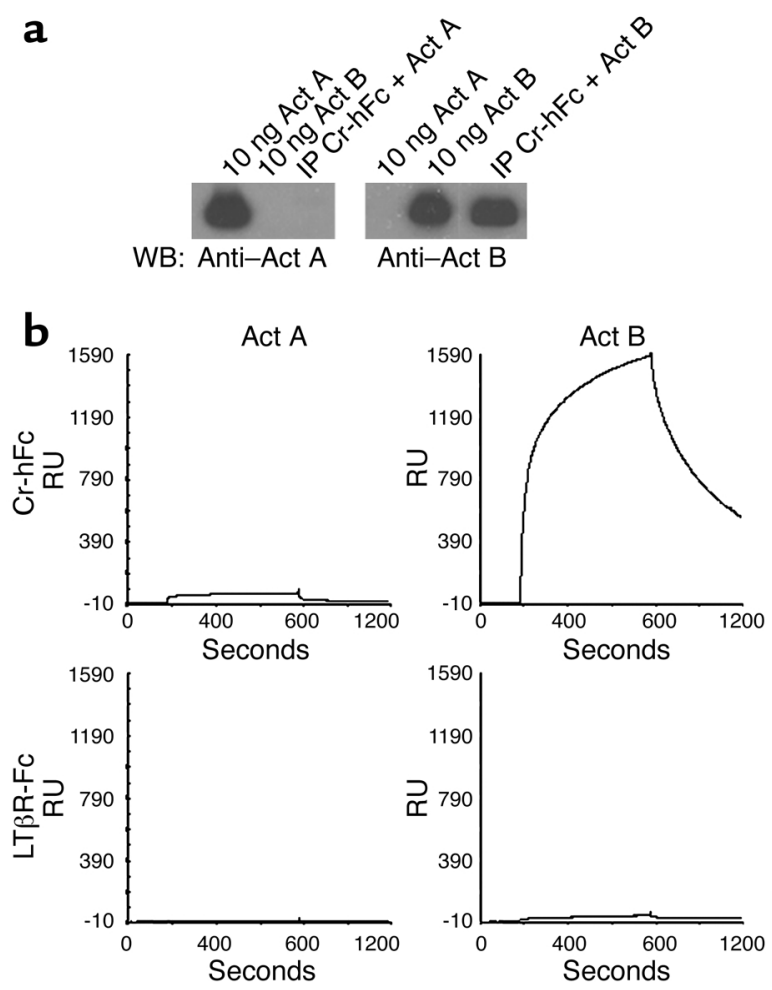

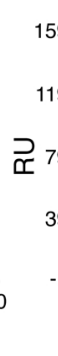

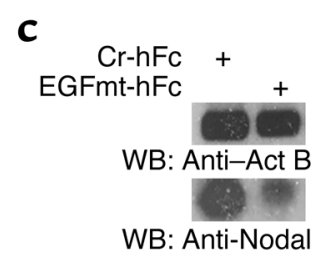

d

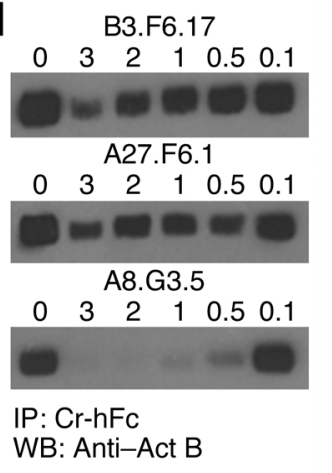


a

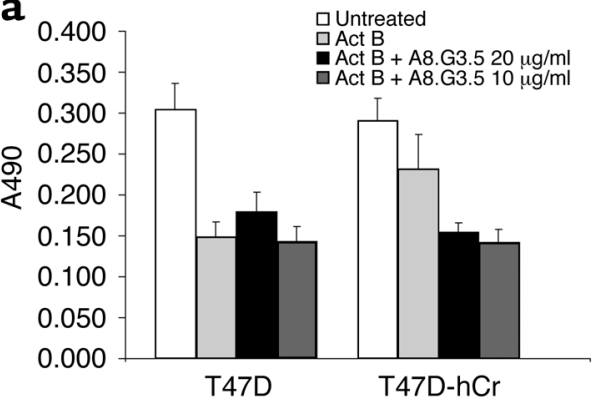

C

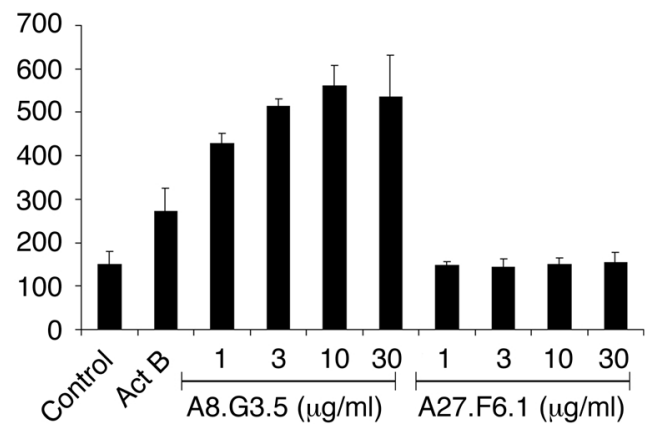

b

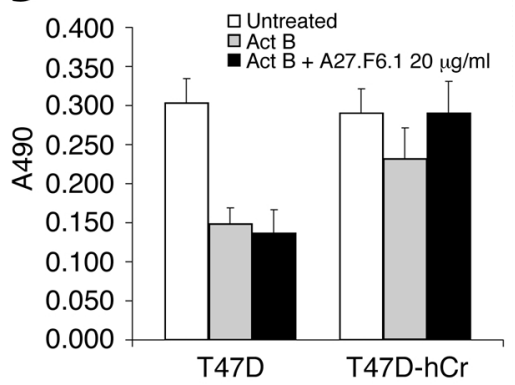

Figure 5

Anti-CFC domain mAb A8.G3.5 restores Act $B$-induced growth inhibition. (a) T47D or T47D-hCr cells grown in media alone (white bars), media with Act B (light gray bars), or media with Act B plus $20 \mu \mathrm{g} / \mathrm{ml}$ A8.G3.5 (black bars) or $10 \mu \mathrm{g} / \mathrm{ml}$ A8.G3.5 (dark gray bars) were assayed for proliferation after 8 days by an MTT assay. $n=4$; the experiment was repeated at least twice. (b) T47D or T47D-hCr cells grown in media alone (white bars), media with Act $B$ (light gray bars), or media with Act B plus $20 \mu \mathrm{g} / \mathrm{ml} \mathrm{A27.F6.1} \mathrm{(black}$ bars). $n=4$; the experiment was repeated at least twice. (c) T47D-hCr cells were transfected with $(\mathrm{n} 2)_{7-}$ luciferase and FAST, and then treated with Act B with or without A8.G3.5 or A27.F6.1 at $0,1,3,10$, or 30 $\mu \mathrm{g} / \mathrm{ml}$ for 16 hours before luciferase reading $(P<0.005$ for each dose). performed as described earlier. Only the anti-CFC $\mathrm{mAb}$ A8.G3.5 inhibited Cripto's ability to interact with Act B (Figure 4d). These data suggest that the CFC domain of Cripto, which interacts with Alk4, is also an important domain for association with Act B and further support the conclusion that Cripto's interactions with Act $B$ and Nodal utilize different residues on Cripto.

Anti-CFC antibody A8. G3.5 restores Act B-induced growth suppression in Cripto-overexpressing cells. Due to the observation that anti-CFC mAb A8.G3.5 can block CriptoAct $\mathrm{B}$ interactions, we tested this antibody for disrupting Cripto's inhibitory effect on Act B signaling in T47D cells. Indeed, when T47D-hCr cells were treated with Act B in the presence of the anti-CFC $\mathrm{mAb}$ A8.G3.5, growth suppression was restored (Figure 5a). Anti-EGF mAb A27.F6.1, by contrast, was unable to restore Act $B$ growth suppression of these cells (Figure $5 b)$. Neither $m A b$ had any effect on the response of the parental T47D cells to Act B. To address whether A8.G3.5 restores Act B signaling through the Smad pathway, we tested whether A8.G3.5 could increase an Act B-induced FAST/(n2) 7 -luciferase response in T47D-hCr cells. T47D-hCr cells are weakly responsive to Act B signaling, but in the presence of A8.G3.5, there was an increase in signal in a dose-dependent manner (Figure 5c). However, A27.F6.1, which does not block Cripto-Act B interactions, was unable to increase the Act $B$ response. These results suggest that, to deregulate Act $B$ growth suppression, Cripto sequesters Act B from its receptors, possibly by also binding Alk4 and excluding ActRII, and prevents Act $B$ from sending growth control signals.

Cripto $m A b$ 's that block Cripto signaling functions in vitro inhibit tumor growth in vivo. To test whether Cripto acts as a signaling molecule to promote tumor growth, we examined the efficacy of Cripto anti-EGF mAb A27.F6.1, which blocks Cripto-Nodal signaling (Figure 2a), and anti-CFC mAb A8.G3.5, which blocks both Cripto-Nodal signaling and Cripto-Act B interactions (Figures $2 \mathrm{c}, 4 \mathrm{~d}$, and $5 \mathrm{a}$ ), in two tumor xenograft models. These "blocking" mAb's were compared with anti-N-terminal mAb's of the same isotype class $\left(\operatorname{IgG}_{1}\right)$ and similar affinity, A10.B2.18 or B3.F6.18, which do not block these activities ("binding" mAb's). Human NCCIT testicular and GEO colon carcinoma cell lines, which express cell surface Cripto (Figure 1) and readily form tumors in nude mice, were chosen for these experiments.

In these studies, antibodies were administered to mice implanted subcutaneously with NCCIT or GEO cells. The experimental groups were compared with control groups including vehicle, cisplatinum chemotherapy, and control anti-myc mAb 9E10. In the NCCIT xenograft experiments, anti-EGF mAb A27.F6.1 at 1 or $10 \mathrm{mg} / \mathrm{kg}$ concentration showed a modest reduction of tumor growth, by about $30 \%(n=10, P=0.05)$ (Figure 6a). However, Cripto anti-CFC mAb A8.G3.5 at 10 $\mathrm{mg} / \mathrm{kg}$ inhibited growth by $70 \%(n=10, P<0.001)$ (Figure $6 \mathrm{~b}$ ). Lower concentrations of A8.G3.5 (1 and 3 $\mathrm{mg} / \mathrm{kg}$ ) inhibited tumor growth by about $55 \%$ in other independent studies (data not shown). By contrast, binding mAb A10.B2.18, which does not block Cripto function, did not inhibit NCCIT tumor growth (Figure $6 c)$. The negative control anti-myc antibody $9 \mathrm{E} 10 \mathrm{had}$ no effect on tumor size compared with vehicle (data not shown). Each double-blinded, randomized study was performed at least twice. ELISA analysis of tumor lysates from control and therapeutic $\mathrm{mAb}$ groups indicated that the Cripto antibodies localized to the tumor site, whereas 9E10 did not (data not shown). 
Anti-CFC mAb A8.G3.5 was tested in a second xenograft model, GEO colon carcinoma cells expressing high levels of Cripto, because Cripto overexpression has been observed in $80 \%$ of colon carcinomas examined (4). A8.G3.5 also exhibited anti-tumor-growth activity in this model, with approximately $50 \%$ reduction in tumor growth at $3 \mathrm{mg} / \mathrm{kg}(P=0.05)$ (Figure 6d). Conversely, $\mathrm{N}$-terminal binding $\mathrm{mAb}$ B3.F6.17 at $10 \mathrm{mg} / \mathrm{kg}$ had no effect on GEO cell tumor growth (Figure 6e). These results indicate that anti-CFC mAb A8.G3.5, which blocks Cripto's ability to modulate both the Act B and the Nodal pathways, is more efficacious in inhibiting tumor growth in vivo than anti-EGF mAb A27.F6.1, which inhibits only the Cripto-Nodal pathway. Both mAb's have similar binding affinities and internalization profiles (M. Jarpe, unpublished data); thus, the difference in activities is likely a result of differences in the blocking of Cripto signaling functions.

To address the possible contributions of Nodal and/or Act B to tumor growth in these two tumor a

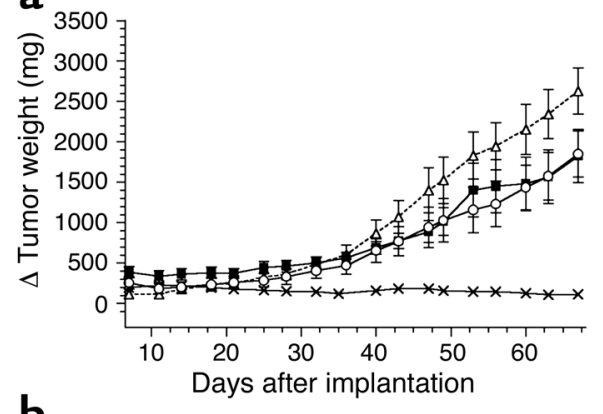

b

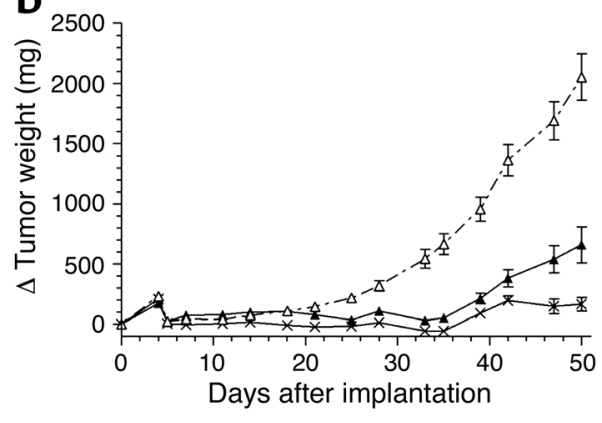

d

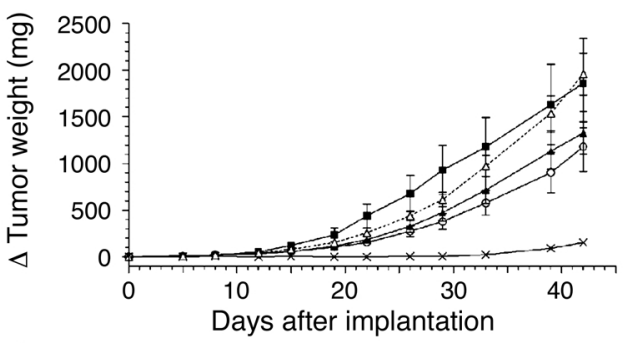

e

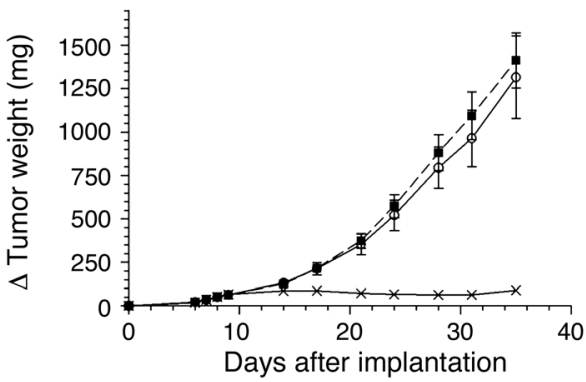

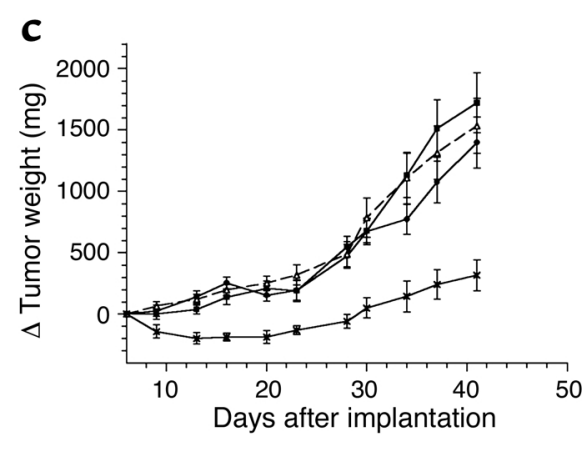

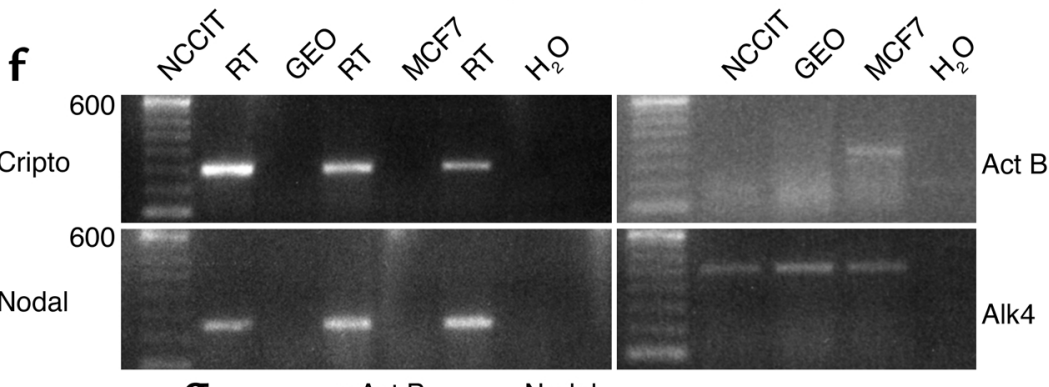

Figure 6

Anti-CFC domain mAb blocks NCCIT and GEO tumor growth in vivo. (a) Response of NCCIT xenograft to A27.F6.1: vehicle control (open triangles), cis-platinum (cross-hatches), $1 \mathrm{mg} / \mathrm{kg} \mathrm{A27.F6.1} \mathrm{(filled} \mathrm{squares),} 10 \mathrm{mg} / \mathrm{kg} \mathrm{A27.F6.1} \mathrm{(open} \mathrm{circles).} \mathrm{(b)} \mathrm{Response} \mathrm{of} \mathrm{NCCIT}$ xenograft to A8.G3.5: vehicle control (open triangles), cis-platinum (cross-hatches), $10 \mathrm{mg} / \mathrm{kg} \mathrm{A8.G3.5} \mathrm{(closed} \mathrm{triangles).} \mathrm{(c)} \mathrm{Response}$

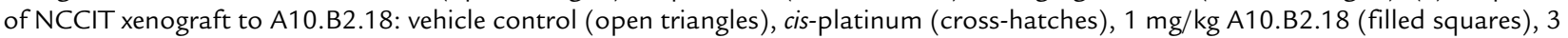
$\mathrm{mg} / \mathrm{kg}$ A10.B2.18 (filled circles). (d) Response of GEO xenograft to A8.G3.5: vehicle control (open triangles), cis-platinum (cross-hatches), $1 \mathrm{mg} / \mathrm{kg}$ A8.G3.5 (filled squares), $3 \mathrm{mg} / \mathrm{kg}$ A8.G3.5 (open circles), $10 \mathrm{mg} / \mathrm{kg} \mathrm{A8.G3.5} \mathrm{(filled} \mathrm{triangles).} \mathrm{(e)} \mathrm{Response} \mathrm{of} \mathrm{GEO} \mathrm{cell}$ xenograft to B3.F6.17: vehicle control (filled squares), cis-platinum (cross-hatches), $10 \mathrm{mg} / \mathrm{kg} \mathrm{B3.F6.17} \mathrm{(open} \mathrm{circles).} \mathrm{(f)} \mathrm{RT-PCR} \mathrm{expres-}$ sion analysis of mRNA transcripts for Cripto, Alk4, Nodal, and Act B in GEO, NCCIT, or MCF-7 cells. Controls include samples without reverse transcriptase (-RT) and samples in which template was replaced with $\mathrm{H}_{2} \mathrm{O}$. (g) RT-PCR expression analysis of mRNA transcripts for murine Act B or human Nodal in NCCIT xenograft tumor sample. 

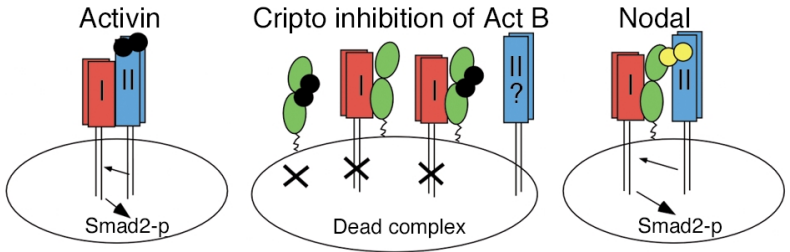

\section{Figure 7}

Model of Cripto's inhibition of Act B signaling through the Smad2 pathway. Left: Activin (black) signaling via Alk4 (red), ActRII (blue), and Smad2 leads to regulated cell proliferation in many tissues and organs. Right: Cripto-dependent Nodal (yellow) signaling through Smad2 leads to differentiation and patterning in the early embryo. Cripto is represented in green. Center: Cripto inhibits Act B signaling via binding to Alk4 and Act B, resulting in deregulated growth and hyperproliferation. Three possible inhibitory complexes are proposed: Cripto/Act B, Cripto/Alk4, and Cripto/Act B/Alk4. Smad2-p, phospho-Smad2.

models, we examined the expression of human Nodal, Act B, Cripto, and Alk4 expression by RT-PCR in NCCIT and GEO cells. As expected, both cell lines express Alk4 and Cripto (Figure 6f). We also observed expression of a Nodal transcript in both cell lines, suggesting that this embryonic gene can be re-expressed in human tumors. This result is in agreement with our studies documenting Nodal mRNA expression in a number of human tumor cell lines (see Supplemental Table 1; www.jci.org/cgi/content/full/112/4/575/DC1). Act B expression was not detected in the NCCIT or GEO cell lines by this method, whereas a faint band was seen in the control MCF-7 breast cancer line (Figure 6f). However, Act B is known to be able to act in a paracrine fashion either from a stromal source or in circulation (18), so we analyzed NCCIT xenograft tumors for the presence of murine Act B that could be supplied by the host mouse. RNA was extracted from the tumor sample and subjected to RT-PCR analysis for murine Act B and human Nodal expression. Using primers specific for murine Act $B$, an approximately 350-bp band was detected (Figure 6g). This DNA fragment was isolated and sequenced to verify that it was indeed a fragment of murine Act B. As expected, a human Nodal PCR product was observed (Figure 6g), and its sequence was confirmed since NCCIT cells express Nodal (Figure 6f). Thus, both Nodal and Act B are available to the tumor in vivo, so we cannot at this time distinguish between the relative contributions of these ligands to tumor growth.

\section{Discussion}

In the present study, we investigated the role of Cripto in mediating signaling by Nodal and Activin, two TGF- $\beta$ ligands that use Alk 4 and ActRII to signal, and blockade of these functions with anti-Cripto mAb's targeted to the EGF and CFC domains. We report, for the first time to our knowledge, that Cripto can bind directly to Act B and antagonize its ability to elicit a growthinhibitory response. We show that Act B interacts with a Cripto fucosylation mutant, whereas Nodal does not, indicating that these ligands interact with different epitopes on Cripto. Both ligands were found to be present in xenograft tumor samples, indicating that both could play a role in promoting tumor cell growth. Furthermore, we demonstrate that an anti-EGF domain antibody, A27.F6.1, blocks Cripto-Nodal signaling and that an anti-CFC domain antibody, A8.G3.5, blocks both Cripto-Nodal signaling and Cripto-Act B interactions. While both antibodies inhibited tumor growth in vivo, A8.G3.5 was a more potent inhibitor, suggesting that antibodies that block the signaling activities mediated by Cripto's CFC domain are the most important class for therapeutic development.

Our data show that overexpression of Cripto antagonizes Act $B$ growth suppression of breast cancer cells. Activin, like TGF- $\beta$, has been proposed to play a tumorsuppressive role in normal tissues (18). Because many tumor cell lines lose responsiveness to Activin, loss of growth suppression by Activin is probably an important early step in tumorigenesis in some cell types. Alterations in the Activin pathway have been noted in many cancers, including reduced receptor expression in prostate or breast cancer cells $(23,24)$ and Alk 4 mutations in pancreatic cancer (23). Therefore, overexpression of Cripto may represent yet another way to deregulate the Activin pathway, in addition to mutation or loss of receptor expression. Addition of anti-CFC $\mathrm{mAb}$ A8.G3.5 reversed the Cripto inhibition of Act $B$ growth suppression and prevented Act B from binding Cripto, whereas an anti-EGF $m A b$ had no effect. This result indicates that Cripto inhibition of Activin signaling is mediated by its CFC domain. In our model, we suggest that Cripto blocks Act B signaling by binding and sequestering Act B from the type II receptor and/or forming nonproductive complexes with Alk4 (Figure 7). One could also envision that overexpression of Cripto could block Act A signaling by sequestering Alk4, but we have not seen this activity in our experiments to date. Both the Cripto-Act B and the Cripto-Alk4 binding activities can be blocked by A8.G3.5; however, the specificity of Cripto for Act B would suggest that binding Act $B$ is important. At this point, formation of a trimeric "dead signaling complex" among Cripto, Alk4, and Act $\mathrm{B}$ (Figure 7) cannot be ruled out and might be confirmed by further experimentation.

While this paper was in review, Gray et al. (39) published a study demonstrating Cripto antagonism of Act A signaling. They show by cross-linking experiments that Cripto can associate with Act A and ActRII when these receptors are overexpressed in 293 cells. Unlike our data, which demonstrate a direct interaction between Cripto and Act B, but not Act A, Gray et al. observe Act A cross-linking to Cripto only in the presence of ActRII. In addition, while they observe that Cripto antagonizes Act A signaling in a luciferase assay, we have never observed an effect of Cripto overexpression on Act A-induced growth suppression, an important biological consequence of Activin signaling. These 
discrepancies may reflect different sources of Act A or different cell lines. Furthermore, Gray et al. show that an EGF domain deletion mutant does not associate with Act A and conclude that Act A and Nodal have similar or overlapping sites of interaction on Cripto. In contrast, we observe binding of Act $\mathrm{B}$ to a Cripto EGF domain fucosylation mutant, hCr(N85G/T88A). Nodal does bind hCr(N85G/T88A), indicating that these residues are important for Nodal binding, but not for Act $\mathrm{B}$ binding. Moreover, we show that only the anti-CFC domain antibody is able to block Act $\mathrm{B}$ from binding Cripto. Thus, while we cannot rule out possible contributions of the EGF domain to binding of Act $\mathrm{B}$, we conclude that the $\mathrm{CFC}$ domain residues are critical for Cripto-Act B interaction.

That Cripto can bind directly to Act B demonstrates that Cripto can modulate other TGF- $\beta$ ligands besides Nodal. Thus, Cripto may be a more general modulator of ligand access to cell surface receptors than was previously known. Other examples of cell surface proteins shown to modulate TGF- $\beta$ family ligand access to receptors include Inhibin-binding protein (40), $\beta$-glycan (41), and the GDNF ligand coreceptors GFR $\alpha 1-4$ (42-44). While this paper was in review, Cheng et al. (45) demonstrated that Cripto interacts with Vg1/GDF1 as a required coreceptor for signaling during embryogenesis. Thus, it will be important to determine whether GDF1 is re-expressed in cancer and how Cripto's interaction with GDF1, Nodal, and Act B is regulated. Because we show that Act B can bind to a Cripto fucosylation mutant, but Nodal binding to this mutant is impaired, it is intriguing to speculate that Cripto's fucosylation state may play a role in allowing differential articulation of Nodal and Activin signals, similar to the way fucosylation of Notch's EGF-like repeat modifies its ligand sensitivity to Delta and Serrate (46-49).

In vivo, A8.G3.5 is the most potent Cripto mAb, inhibiting tumor volume by up to $70 \%$ in doubleblinded, randomized NCCIT xenograft studies. While it is formally possible that the inhibition of tumor growth results from a mechanism other than blockade of Cripto's function, nonblocking anti$\mathrm{N}$-terminal Cripto mAb's of the same isotype class $\left(\mathrm{IgG}_{1}\right)$ and similar affinity (A10.B2.18 and B3.F6.17) had no effect on tumor growth in both NCCIT and GEO xenograft models. In addition, preliminary experiments with a nonblocking anti-CFC Cripto $\mathrm{mAb}$ that did not interfere with Cripto-Nodal signaling or Cripto-Alk4 interactions in vitro had no effect on NCCIT tumor growth in vivo (see Supplemental Figure 3; www.jci.org/cgi/content/full/112/ 4/575/DC1). In contrast, anti-EGF mAb A27.F6.1, which blocks only the Cripto-Nodal signaling pathway, but not Cripto's antagonism of Act B, had marginal yet reproducible inhibition of tumor growth, by about $30 \%$. This result suggests that blockade of both pathways by targeting of the CFC domain may be important for efficacy in vivo. These results validate the therapeutic hypothesis that functional blockade of Cripto inhibits tumor growth and point to the anti-CFC domain mAb's as a potentially important class of mAb's for further development.

We propose that, like loss of TGF- $\beta$ responsiveness, loss of Activin responsiveness may be an important early step in cell transformation, and Cripto overexpression may mediate the loss of Act B signaling in some tissues by antagonizing Act B growth inhibition. In fact, Cripto protein expression as an early indicator of tumor progression has been cited as a possible marker to track dysplasia to breast tumor formation (4). Later in tumorigenesis, whether Cripto functions by facilitating signaling from Nodal or antagonizes Act $\mathrm{B}$ activity is not known. In the fully transformed cell lines NCCIT and GEO, we detected Nodal RNA expression, indicating that Cripto could be facilitating positive signals from Nodal to promote tumor growth. We have also observed Nodal transcripts in a variety of lung, colon, and breast carcinoma cell lines (see Supplemental Table 1; www.jci.org/cgi/content/ full/112/4/575/DC1), suggesting that even though Nodal is not known to be widely expressed in adult tissue, it may be re-expressed in tumors. The lack of active, purified Nodal protein in the field and the absence of Nodal mAb's have left the question of whether Nodal protein is expressed in human tumor samples unanswered for the present. We also detected murine Act B RNA expression in the NCCIT xenograft tumor, indicating that Act B is expressed from stromal sources and is available to the tumor cells. Thus, at this time we cannot distinguish between the contributions of Nodal and Act B in stimulating growth of these tumors, nor between the contributions of other TGF- $\beta$ family members with which Cripto may interact, such as GDF1 (45).

In summary, we generated Cripto antibodies that recognize epitopes critical for Cripto function and used them to dissect Cripto's ability to modulate Nodal and Act B signaling in cancer cells. We demonstrated that Cripto can bind and disrupt Act B growth inhibition, highlighting a possible new mechanism by which Cripto could promote cell transformation. We also detected Nodal expression in human tumor cell lines, suggesting that Cripto may facilitate positive growth-promoting signals from Nodal in cancer. Furthermore, we show that by targeting the CFC domain of Cripto with mAb A8.G3.5, we can block both Cripto-Nodal signaling and Cripto-Act B antagonism. In vivo, A8.G3.5 exhibited the greatest activity, inhibiting tumor growth by up to $70 \%$, suggesting that targeting the multiple functions of Cripto's CFC domain could be important for achieving the greatest efficacy in vivo. Thus, the ability of Cripto antibodies to inhibit tumor growth defines Cripto as an important oncogene and blocking of anti-CFC Cripto mAb's as an important new therapeutic approach for treatment of human solid tumors. 


\section{Acknowledgments}

The authors wish to thank Joan Brugge, Malcolm Whitman, Dan Haber, Martin Scott, Brian Elenbaas, Stephen Fawell, Victor Koteliansky, and Richard Cate for critical reading of the manuscript. We thank Cindy Bottiglio, Kendall Szeliga, and Rebecca Kelly for expertise in performing animal xenograft studies. We are especially grateful to Carl-Henrik Heldin, Malcolm Whitman, and Michael Shen for sharing reagents. We also thank the FACS and DNA sequencing facilities at Biogen Inc. for expert technical support. Nicola Normanno was supported by a grant from the Associazione Italiana per la Ricerca sul Cancro.

1. Gibbs, J.B. 2000. Anticancer drug targets: growth factors and growth factor signaling. J. Clin. Invest. 105:9-13.

2. de Bono, J.S., and Rowinsky, E.K. 2002. The ErbB receptor family: a therapeutic target for cancer. Trends Mol. Med. 8(Suppl. 4):S19-S26.

3. George, D. 2001. Platelet-derived growth factor receptors: a therapeutic target in solid tumors. Semin. Oncol. 28:27-33.

4. Adamson, E.D., Minchiotti, G., and Salomon, D.S. 2002. Cripto: a tumor growth factor and more. J. Cell. Physiol. 190:267-278.

5. Ciardiello, F., et al. 1994. Inhibition of CRIPTO expression and tumorigenicity in human colon cancer cells by antisense RNA and oligodeoxynucleotides. Oncogene. 9:291-298.

6. Brennan, J., et al. 2001. Nodal signalling in the epiblast patterns the early mouse embryo. Nature. 411:965-969.

7. Ding, J., et al. 1998. Cripto is required for correct orientation of the anterior-posterior axis in the mouse embryo. Nature. 395:702-707.

8. Gritsman, K., et al. 1999. The EGF-CFC protein one-eyed pinhead is essential for nodal signaling. Cell. 97:121-132.

9. Shen, M.M., and Schier, A.F. 2000. The EGF-CFC gene family in vertebrate development. Trends Genet. 16:303-309.

10. Yan, Y.T., et al. 1999. Conserved requirement for EGF-CFC genes in vertebrate left-right axis formation. Genes Dev. 13:2527-2537.

11. Bianco, C., et al. 2002. Cripto-1 activates nodal- and ALK4-dependent and -independent signaling pathways in mammary epithelial cells. Mol. Cell. Biol. 22:2586-2597.

12. Yeo, C., and Whitman, M. 2001. Nodal signals to Smads through Cripto-dependent and Cripto-independent mechanisms. Mol. Cell. 7:949-957.

13. Kumar, A., et al. 2001. Nodal signaling uses activin and transforming growth factor-beta receptor-regulated Smads. J. Biol. Chem. 276:656-661.

14. Bianco, C., et al. 2002. Detection and localization of Cripto-1 binding in mouse mammary epithelial cells and in the mouse mammary gland using an immunoglobulin-cripto-1 fusion protein. J. Cell. Physiol. 190:74-82.

15. Schiffer, S.G., et al. 2001. Fucosylation of Cripto is required for its ability to facilitate nodal signaling. J. Biol. Chem. 276:37769-37778.

16. Barcellos-Hoff, M.H., and Ewan, K.B. 2000. Transforming growth factor-beta and breast cancer: mammary gland development. Breast Cancer Res. 2:92-99.

17. Derynck, R., Akhurst, R.J., and Balmain, A. 2001. TGF-beta signaling in tumor suppression and cancer progression. Nat. Genet. 29:117-129.

18. Risbridger, G.P., Schmitt, J.F., and Robertson, D.M. 2001. Activins and inhibins in endocrine and other tumors. Endocr. Rev. 22:836-858.

19. Wakefield, L.M., and Roberts, A.B. 2002. TGF-beta signaling: positive and negative effects on tumorigenesis. Curr. Opin. Genet. Dev. 12:22-29.

20. Muraoka, R.S., et al. 2002. Blockade of TGF- $\beta$ inhibits mammary tumor cell viability, migration, and metastases. J. Clin. Invest. 109:1551-1559. doi:10.1172/JCI200215234.

21. Yang, Y.A., et al. 2002. Lifetime exposure to a soluble TGF- $\beta$ antagonist protects mice against metastasis without adverse side effects. J. Clin. Invest. 109:1607-1615. doi:10.1172/JCI200215333.

22. van Schaik, R.H., et al. 2000. Variations in activin receptor, inhibin/ activin subunit and follistatin mRNAs in human prostate tumour tissues. Br. J. Cancer. 82:112-117.

23. Su, G.H., et al. 2001. ACVR1B (ALK4, activin receptor type 1B) gene mutations in pancreatic carcinoma. Proc. Natl. Acad. Sci. U. S. A. 98:3254-3257.
24. Kalkhoven, E., et al. 1995. Resistance to transforming growth factor beta and activin due to reduced receptor expression in human breast tumor cell lines. Cell Growth Differ. 6:1151-1161.

25. Adkins, H.B., Blacklow, S.C., and Young, J.A. 2001. Two functionally distinct forms of a retroviral receptor explain the nonreciprocal receptor interference among subgroups B, D, and $\mathrm{E}$ avian leukosis viruses. J. Virol. 75:3520-3526.

26. Johnsson, B., Lofas, S., and Lindquist, G. 1991. Immobilization of proteins to a carboxymethyldextran-modified gold surface for biospecific interaction analysis in surface plasmon resonance sensors. Anal. Biochem. 198:268-277.

27. Alexander, J.M., Bikkal, H.A., Zervas, N.T., Laws, E.R., Jr., and Klibanski, A. 1996. Tumor-specific expression and alternate splicing of messenger ribonucleic acid encoding activin/transforming growth factor-beta receptors in human pituitary adenomas. J. Clin. Endocrinol. Metab. 81:783-790.

28. Normanno, N., et al. 1995. Expression of messenger RNA for amphiregulin, heregulin, and cripto-1, three new members of the epidermal growth factor family, in human breast carcinomas. Breast Cancer Res. Treat. 35:293-297.

29. Normanno, N., et al. 2003. CRIPTO-1 overexpression leads to enhanced invasiveness and resistance to anoikis in human MCF-7 breast cancer cells. J. Cell. Physiol. In press.

30. Albano, R.M., Groome, N., and Smith, J.C. 1993. Activins are expressed in preimplantation mouse embryos and in ES and EC cells and are regulated on their differentiation. Development. 117:711-723.

31. Yan, Y.T., et al. 2002. Dual roles of Cripto as a ligand and coreceptor in the nodal signaling pathway. Mol. Cell. Biol. 22:4439-4449.

32. Qi, C.F., et al. 1994. Expression of transforming growth factor alpha, amphiregulin and cripto-1 in human breast carcinomas. Br. J. Cancer. 69:903-910.

33. Saeki, T., et al. 1995. Association of epidermal growth factor-related peptides and type I receptor tyrosine kinase receptors with prognosis of human colorectal carcinomas. Jpn. J. Clin. Oncol. 25:240-249.

34. Chen, Y.G., Lui, H.M., Lin, S.L., Lee, J.M., and Ying, S.Y. 2002. Regulation of cell proliferation, apoptosis, and carcinogenesis by activin. Exp. Biol. Med. (Maywood). 227:75-87.

35. Cocolakis, E., Lemay, S., Ali, S., and Lebrun, J.J. 2001. The p38 MAPK pathway is required for cell growth inhibition of human breast cancer cells in response to activin. J. Biol. Chem. 276:18430-18436.

36. Liu, Q.Y., et al. 1996. Inhibitory effects of activin on the growth and morpholgenesis of primary and transformed mammary epithelial cells. Cancer Res. 56:1155-1163.

37. Hahn, W.C., et al. 1999. Creation of human tumour cells with defined genetic elements. Nature. 400:464-468.

38. Kannan, S., et al. 1997. Cripto enhances the tyrosine phosphorylation of Shc and activates mitogen-activated protein kinase (MAPK) in mammary epithelial cells. J. Biol. Chem. 272:3330-3335.

39. Gray, P.C., et al. 2003. Cripto forms a complex with activin and type II activin receptors and can block activin signaling. Proc. Natl. Acad. Sci. U. S. A. 100:5193-5198.

40. Chong, H., et al. 2000. Structure and expression of a membrane component of the inhibin receptor system. Endocrinology. 141:2600-2607.

41. Massague, J., and Chen, Y.G. 2000. Controlling TGF-beta signaling. Genes Dev. 14:627-644.

42. Jing, S., et al. 1996. GDNF-induced activation of the ret protein tyrosine kinase is mediated by GDNFR-alpha, a novel receptor for GDNF. Cell. 85:1113-1124.

43. Sanicola, M., et al. 1997. Glial cell line-derived neurotrophic factordependent RET activation can be mediated by two different cell-surface accessory proteins. Proc. Natl. Acad. Sci. USA. 94:6238-6243.

44. Treanor, J.J., et al. 1996. Characterization of a multicomponent receptor for GDNF. Nature. 382:80-83.

45. Cheng, S.K., Olale, F., Bennett, J.T., Brivanlou, A.H., and Schier, A.F. 2003. EGF-CFC proteins are essential coreceptors for the TGF-beta signals Vg1 and GDF1. Genes Dev. 17:31-36.

46. Bruckner, K., Perez, L., Clausen, H., and Cohen, S. 2000. Glycosyltransferase activity of Fringe modulates Notch-Delta interactions. Nature. 406:411-415.

47. Hicks, C., et al. 2000. Fringe differentially modulates Jagged 1 and Delta1 signalling through Notch1 and Notch2. Nat. Cell Biol. 2:515-520.

48. Moloney, D.J., et al. 2000. Fringe is a glycosyltransferase that modifies Notch. Nature. 406:369-375.

49. Moloney, D.J., et al. 2000. Mammalian Notch1 is modified with two unusual forms of O-linked glycosylation found on epidermal growth factor-like modules. J. Biol. Chem. 275:9604-9611. 